\title{
Oligomerization of hexafluoropropylene oxide in the presence of alkali metal halides
}

\author{
Egbert Meissner, Agnieszka Wróblewska \\ Szczecin University of Technology, Institute of Organic Chemical Technology, ul. Pułaskiego 10, 70-322 Szczecin, Poland, \\ e-mail: Egbert.Meissner@ps.pl
}

\begin{abstract}
Oligomers of hexafluoropropylene oxide are raw materials for the synthesis of compounds having unique properties such as high chemical and thermal resistance. Two basic parameters have influence on the process of hexafluoropropylene oxide oligomerization: the kind of the catalyst and the solvent. The temperature and pressure influence this process to a lesser extent. The influence of halide ions, the solvent and the temperature on the oligomerization of hexafluoropropylene oxide has been studied.
\end{abstract}

Keywords: heksafluoropropylene oxide, oligomers of hexafluoropropylene oxide.

Presented at VII Conference Wasteless Technologies and Waste Management in Chemical Industry and Agriculture, Międzyzdroje, 12 - 15 June, 2007.

\section{INTRODUCTION}

The products of hexafluoropropylene oxide (HFPO) oligemorization are oligomers with the structure of a linear polyether terminated with a fluorocarbonyl group:

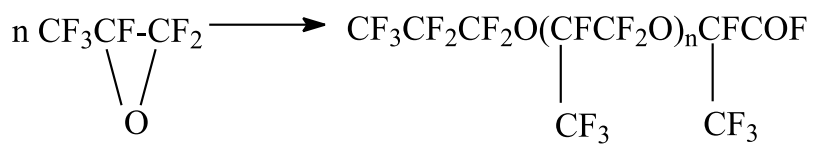

where: $\mathrm{n}$ can have values $0-10$

The first stage of the oligomerization is the isomerization of the HFPO to perfluoropropionic acid fluoride as a result of the attack of nucleophilic reactant at the ambient temperature. The attack takes place generally on the $\mathrm{C} 3$ carbon. The $\mathrm{C} 2$ carbon can also be attacked but less frequently. Tertiary and secondary amines, enamines and halide ions can be applied as nucleophilic reactants:
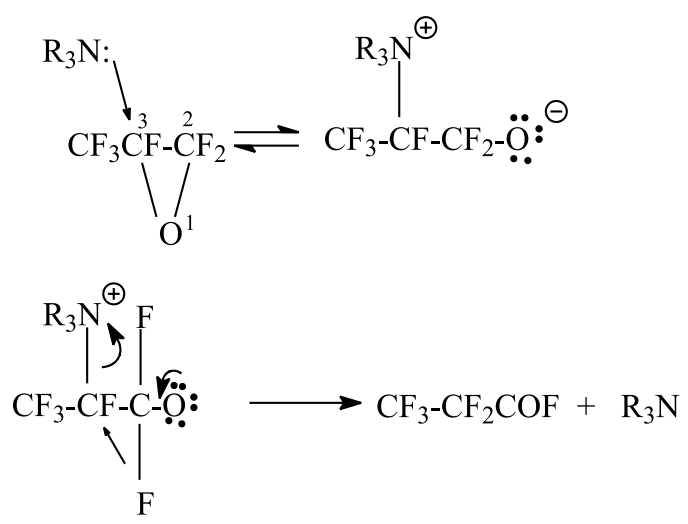

The perfluoropropionic acid fluoride is in equilibrium with the ion of the perfluoropropionic oxide, which in the reaction with the HFPO molecule gives the alkoxy compound $(n=1)$. By eliminating the fluoride ion, the alkoxy compound transforms into acid fluoride. The addition of more HFPO is possible $(n>1)$.

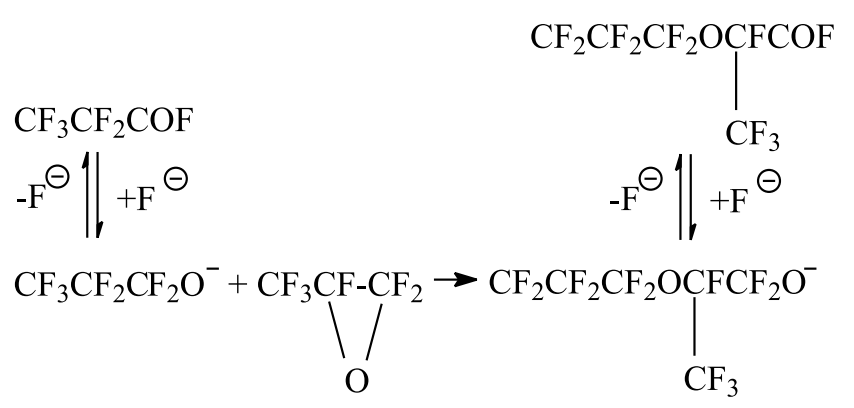

The degree of oligomerization depends on the kind of the catalyst, the conditions of the reaction and on the clearness of the HFPO. Oligomerization can be performed in such a way in order to receive dimers with the maximum yield, from which after the transformation, monomers in the form of perfluoropropylvinyl ethers are obtained. Trimers and tetramers are valuable intermediates for the synthesis of surface active agents with oleofobic polyfluorinated chain, which are worth mentioning because of their unique qualities. Higher olimers of the HFPO demonstrating high thermostable and chemical resistance have been found to be as useful as oil.

The reason for taking up the issue of oligomerization of the HFPO is the high applicability of the polyfluorinated surface active agents and their rather small availability on the local market and high price. The aim of the work was to examine the influence of the oligomerization catalysts on the synthesis of trimers and tetramers of HFPO with the maximum yield. The length of the fluoroorganic chain corresponding to trimer and tetramer has the best surface properties.

\section{EXPERIMENTAL}

The oligomerization process was performed in an autoclave from Berghoff (Germany) with the capacity of 200 $\mathrm{cm}^{3}$ made of the chromium-nickiel-molybdenic steel. The cover of the autoclave was equipped with: two needle valves, thermocouple, manometer and the safety plate. A weighed amount of the catalyst, previously ground and roasted was put into the dry autoclave, and then $50 \mathrm{~cm}^{3}$ of dry acetonitrile was added. After covering the autoclave some proper amount of HFPO was put under the solvent 
while the mixture was stirred intensively. The reaction temperature from -10 to $+40^{\circ} \mathrm{C}$ was maintained by immersing the autoclave in a thermostated water-ethylene glycol mixture. The pressure inside the autoclave was kept constant by means of a second valve connected to a cryostat $\left(-50^{\circ} \mathrm{C}\right)$. The products of the HFPO oligomerization were analyzed as methyl esters on the gas chromatograph Chrom 5. The chromatographic conditions: $7 \mathrm{~m}$ column with the $3 \mathrm{~mm}$ inner diameter, filled up with $15 \%$ Reoplex 100 deposited on the chromosorb WAW 60/80 mesh, program temperature: isothermally at $50^{\circ} \mathrm{C}$ for 4 minutes and then ramped from 50 to $200^{\circ} \mathrm{C}$ at $20^{\circ} \mathrm{C} / \mathrm{min}$ rate, detector FID, carrier gas nitrogen $25 \mathrm{~cm}^{3} / \mathrm{min}$, the volume of the sample $0.3 \mu$ l.

\section{RESULTS}

Firstly, the dependence of the oligomers HFPO yield in heterogenic oligomerization on the kind of initiators was determined. The other parameters such as the amount of aprotic solvent $\left(50 \mathrm{~cm}^{3}\right)$, the temperature $\left(20^{\circ} \mathrm{C}\right)$, the reaction time, pressure and the molar ratio were kept constant. The HFPO oligomerization was performed for 5 hours at $2 \mathrm{~atm}$ and a halide : acetonitrile : HFPO the molar ratio of $1: 10: 5$, respectively. The results received in the oligomerization are presented in Table 1. The results show that by using alkali metal halides, the degree of the HFPO oligomerization decreases in the sentence: $\mathrm{F}, \mathrm{Cl}, \mathrm{Br}$ and I. Oligomerization in the presence of fluoride ion under certain examination conditions leads mainly to trimers and tetramers, in lesser amounts to dimer and pentamer. Iodide ion oligomerizes HFPO mainly to the dimer. The tetramer is created in very little amount. The results correlate well with the sizes of ionic radius of halides and their electronegativity. With the rise in ion radius of the halide its electronegativity decreases, which leads to the decrease of ion nucleophility. As a result, a decrease in nucleophility leads to a decrease in the average degree of the HFPO oligomerization.

Table 1. The dependence of the degree of the THFP oligomerization on the kind of the catalyst

\begin{tabular}{|c|l|c|c|c|c|c|}
\hline \multirow{2}{*}{} & \multirow{2}{*}{ Catalyst } & \multicolumn{6}{|c|}{ Oligomers of THFP, wt\% } \\
\cline { 3 - 7 } & & Dimer & Trimer & Tetramer & Pentamer & Heksamer \\
\hline 1 & $\mathrm{KF}$ & 12.3 & 24.0 & 38.4 & 21.8 & 4.1 \\
\hline 2 & $\mathrm{CsF}$ & 13.9 & 52.8 & 21.0 & 11.6 & 1.2 \\
\hline 3 & $\mathrm{KCl}$ & 31.5 & 46.3 & 19.0 & 3.1 & - \\
\hline 4 & $\mathrm{KBr}$ & 51.5 & 40.2 & 8.4 & - & - \\
\hline 5 & $\mathrm{KI}$ & 82.8 & 12.3 & 5.6 & - & - \\
\hline
\end{tabular}

The next examined parameter was the dependence of the oligomerization degree on the kind of the solvent. KF was used as the catalyst, the reactions with solvents were performed at $20^{\circ} \mathrm{C}$, under $1 \mathrm{~atm}$ pressure, for one hour, at the molar ratio of KF : HFPO : solvent $=1: 50: 5$. The results received are presented in Table 2 .

In the next stage, the influence of the temperature on the yield of the HFPO tetramer was examined. The tests were at a temperature range of $-10^{\circ} \mathrm{C}$ to $+40^{\circ} \mathrm{C}$. Diglyme was used as the solvent and KF as the catalyst. The other conditions were identical as in the previous examinations of the influence of the kind of the catalyst. The received results are presented in Fig. 1.
Table 2. The dependence of the degree of the THFP oligomerization on the kind of the solvent

\begin{tabular}{|l|c|c|c|c|c|c|}
\hline \multirow{2}{*}{ Solvent } & \multicolumn{7}{|c|}{ Oligomers } \\
\cline { 2 - 8 } & $\mathrm{n}=0$ & $\mathrm{n}=1$ & $\mathrm{n}=2$ & $\mathrm{n}=3$ & $\mathrm{n}=4$ & $\mathrm{n}=5$ \\
\hline Tetrahydrofuran & 100 & - & - & - & - & - \\
\hline Acetonitrile & 31 & 53 & 13 & 3 & - & - \\
\hline Glyme & 24 & 29 & 27 & 14 & 6 & - \\
\hline Diglyme & 17 & 27 & 28 & 20 & 8 & - \\
\hline Tetraglyme & 8 & 21 & 30 & 24 & 12 & 5 \\
\hline
\end{tabular}

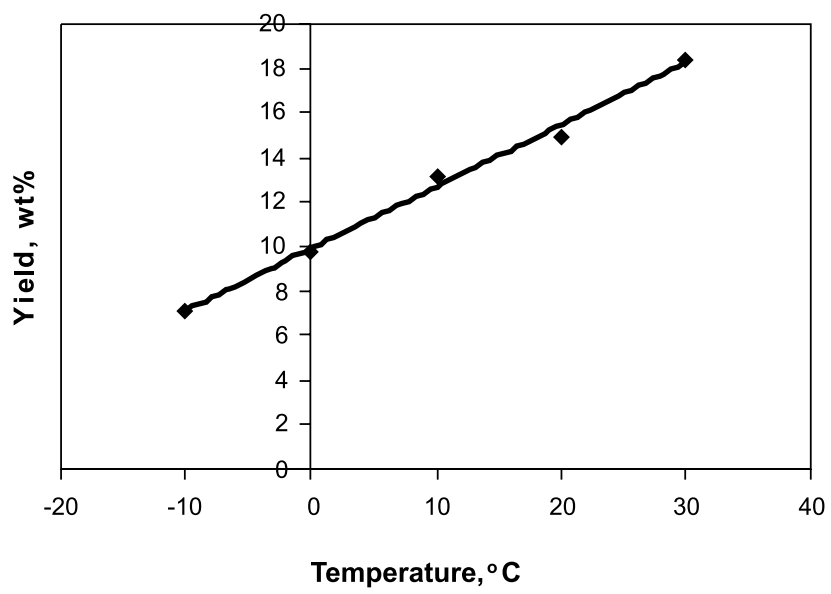

Figure 1. The dependence of the yield of theTHFP trimer on the temperature

\section{CONCLUSION}

The presented results show that in the presence of alkali metals halides, the best catalysts to obtain trimers and tetramers are potassium and cesium fluoride. The condition for successful oligomerization is anhydrous medium and the maximum granulation of the catalyst. Cesium fluoride has severe disadvantages in this aspect for it hydroscopic. It is difficult to maintain the conditions, making the work with cesium fluoride demanding. In the catalytic processes with chloride, bromide and iodide ions, there is a possibility to insert these ions to the structure of oligomers, resulting in the reaction illustrated in the following mechanism:

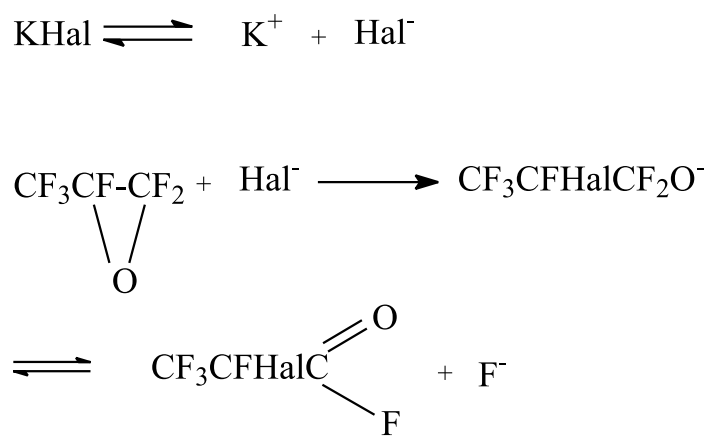

This confirms the phenomenon that oligomers catalyzed by iodine ions take on a bright red color after a long exposure to light.

The next parameter studied was the influence of the aprotic solvent. It was observed that the solubility of halides in the investigated solvents plays an important role. In tetrahydrofuran, alkali metals halides are practically insoluble, thus oligomerization does not proceed in this solvent. Alkali metal halides dissolve poorly in acetonitrile, thus the oligomerization reaction proceeds with 
difficulty. The influence of the solubility of halides is most clearly visible in glymes. The more ether oxides in the molecule of glyme the easier and faster the oligomerization proceeds. This is related to the fact that inorganic salts form with ether oxides of the glyme complexes similar to those with crone ethers. The influence of temperature on the course of the oligomerization is minimal. With an increase in temperature there is an increase in the participation of oligomers with $n>4$.

\section{LITERATURE CITED}

(1) Millauer H., Schwertfleger W., Siegemund G,: Hexafluoropropylene oxide - a key compound in organofluorine chemistry, Angew. Chem. Int. Ed. Engl. 1985, $24,161$.

(2) Strutz H. at al.: Method for the oligomerization of hexafluoropropene oxide, EP 0378797, 1990.

(3) Darling D. T. at al.: Polymerization of hexafluoropropylene oxide, EP 0154297, 1985.

(4) Kuhne $G$ at al.: Process for the dimerization of hexafluoropropylene oxide, US Pat. 4303593, 1981.

(5) Arbogast F.L at al.: Polymerization of hexafluoropropykene oxid, US Pat. 3412148, 1968.

(6) Kruse A. at al.: Verfahren zur herstellung von perfluorienten carbonsaurefluoriden, DE Pat. 3737920, 1989.

(7) Kissa E.: Fluorinated surfactants: synthesis, properties, applications, Surfactant Science series, Marcel Dekker, New York 1994. 